William P. Howlett, PhD

Correspondence to Dr. Howlett: william@williamhowlett.com

See page 654

\section{INFLAMMATORY NEUROLOGIC DISEASE IN SUB-SAHARAN AFRICA}

Inflammation occurs in response to infections or injury and is a sign of a healthy or functioning immune system. Infections involving the nervous system are common in sub-Saharan Africa (SSA), where they account for a sizable proportion of disease and deaths. These are caused by viruses, bacteria, fungi, protozoa, and helminthes, such as cryptococcus, toxoplasma, and tuberculosis (TB) in HIV infection, protozoa in cerebral malaria and trypanosomiasis, and helminthes in neurocysticercosis. Three chapters in the textbook Neurology in Africa ${ }^{1}$ review the direct effects of the main infectious diseases on the nervous system. However, there exists another group of disorders caused by an indirect effect of the immune response about which much less is known in SSA. These are antibody- and inflammatory-mediated and the resulting disorders are generally termed autommune. In this article, I briefly describe the main inflammatory-mediated neurologic disorders affecting the brain, spinal cord, neuromuscular junction, and muscle and describe their impact in SSA.

Brain. Multiple sclerosis. Multiple sclerosis (MS) occurs worldwide and its incidence varies widely depending on latitude, race, and ethnic origin. MS is considered to be either rare or absent in SSA. Its cause is unknown but infection in combination with genetic and environmental factors appears to play a major role. A protective role of increased sunlight exposure and adequate vitamin D3 levels has recently been shown. The Republic of South Africa (RSA), with its racial mixture, genetic diversity, and location, provides an important study site for the disease. In 1967, Dean, ${ }^{2}$ in a study over an 8-year period involving a population of over 15 million Bantu South Africans, reported no cases of MS, while confirming MS to be present in white and mixed-race communities. Notably, the frequency in white participants was highest in emigrants from northern Europe and lowest in Afrikaans-speaking white participants. More recently, Bhigjee et al. ${ }^{3}$ reported age-standardized prevalence rates of MS to be 25.64 per 100,000 in the white population and 0.23 per 100,000 in the black population in RSA. These striking differences support a major role for environmental protection in SSA, and are extensively reviewed by Poser. ${ }^{4}$

Neuromyelitis optica (Devic disease). Neuromyelitis optica (NMO) is an uncommon condition characterized by acute transverse myelitis and optic neuritis with a relapsing course over months to years resulting in severe disability or death. The diagnosis in SSA is mostly clinical but can be confirmed by characteristic MRI findings and serum or CSF autoantibodies that bind to aquaporin- 4 . The incidence of NMO in SSA appears to be similar to worldwide rates, though studies in the SSA population are scarce. In Nigeria in 1971, Osuntokun ${ }^{5}$ reported 95 cases of NMO, compared to just 2 cases of MS observed over the same time period. This agrees with the author's experience in Northern Tanzania. Modi et al. ${ }^{6}$ described a CNS demyelinating disorder with overlapping features of $\mathrm{NMO}$ /acute disseminated encephalomyelitis (ADEM)/ MS in 8 black South Africans. In a recent publication from RSA, 11 out of 14 patients with NMO had active pulmonary tuberculosis, suggesting a shared immunologic mechanism.

Other inflammatory disorders. ADEM is an uncommon disorder with an unknown incidence in SSA. There are reports, however, of cases occurring in children, in HIV-infected patients, in pregnant women, and after vaccinations. Subacute sclerosing encephalitis is caused by delayed immunologic response to persistent measles virus and is inyariably fatal. Incidence rates up to 5 per million have been reported in SSA but its frequency is decreasing with widespread childhood measles immunization. Helminthic infections are common in SSA and neurocysticercosis, with its inflammatory sequelae, is a major cause of epilepsy in endemic areas. CNS vasculitis has been reported mostly in association with HIV and connective tissue diseases, such as systemic lupus erythematosus (SLE), polyarteritis nodosa, Churg-Strauss disease, and temporal arteritis. SLE, though relatively uncommon in tropical SSA, shares a similar but less dramatic tropical gradient pattern with MS. Sarcoidosis is absent from large sections of tropical Africa but has been reported from RSA and Nigeria. Paraneoplastic neurologic syndromes are either very rare or not reported. 
Spinal cord. Paraplegia is a major cause of disability and death in SSA. The leading nontraumatic causes are Pott disease (vertebral TB), malignancy (metastatic), transverse myelopathy (TM), and nutritional (konzo, which is associated with chronic consumption of insufficiently processed bitter cassava). The main causes of TM are infections including HIV, TB, herpes, schistosomiasis, syphilis, and human T-cell lymphotropic virus (HTLV)-1, and inflammation including acute transverse myelitis (ATM), NMO, and ADEM. ATM is a major cause of paraplegia in SSA; its cause is largely unknown but is considered to be viral or autoimmune in origin.

HTLV-1 originated in Africa and is widespread there. Rates of infection vary, the lowest being $<1 \%$ in East Africa and the highest being 1\%-5\% in some southern and western coastal areas and parts of central Africa. HTLV-1-associated myelopathy occurs in $0.3 \%-4 \%$ of infected persons, resulting in endemic foci. A frequency of 50 per 100,000 is reported in Zaire and an association with HIV has been seen in RSA. Its pathogenesis is characterized by chronic inflammation of the spinal cord although the mechanism is unclear.

Neuromuscular junction and muscle. The main inflammatory disorders at the neuromuscular junction and muscle are myasthenia gravis (MG), polymyositis, and dermatomyositis. MG occurs throughout Africa with an incidence of 1.12 per 100,000 in Cape Town (2007), ${ }^{8}$ similar to worldwide incidence. Clinical differences reported in SSA ${ }^{9}$ include treatmentresistant ophthalmoplegia and ptosis, being more common in black than in white South Africans. Polymyositis also occurs throughout Africa, with Osuntokun ${ }^{5}$ documenting a prevalence of 10.7 per 100,000 in Nigeria. The known association with HIV is also reported in RSA but with a younger age at onset, female preponderance, and lower CK levels. There are isolated reports mostly from RSA of uncommon neuromuscular disorders including Lambert-Eaton syndrome, stiff-person syndrome, neuromyotonia, and channelopathies.

Peripheral neuropathies. The main causes of peripheral neuropathies in SSA are HIV, diabetes, alcohol, nutrition, and leprosy. HIV-associated sensory neuropathies are now the most common cause. Guillain-Barre syndrome (GBS) and chronic inflammatory demyelinating polyneuropathy are both reported in SSA. An incidence of 0.88 per 100,000 was reported for GBS from Northern Tanzania (1996). ${ }^{10}$ Notable findings in that study were the high mortality rate $(15.3 \%)$ and association with HIV infection (30.5\%). A similar pattern was reported in Zimbabwe (1991). ${ }^{11}$ Leprosy is still endemic in SSA, with approximately 40,000 new cases reported annually. Leprosy is associated with both normal and disordered immunity, the later characterized by inflammatory reversal reactions in immunologically unstable patients as their immunity improves. Other inflammatory neuropathies reported in SSA include optic neuritis, Bell palsy, mononeuropathy, and radiculopathy.

Inflammation and HIV. HIV infection is characterized by loss of immunity or an abnormal inflammatory response. The autoimmune effect in the nervous system is seen with the increased frequency of ADEM, ATM, GBS, and polymyositis. An association with motor neuron disease, also observed by the author, may suggest a shared immunologic mechanism. Immune reconstitution inflammatory syndrome (IRIS) is common in SSA in antiretroviral therapy-treated CNS infections. In a recent study from RSA, IRIS occurred in $47 \%$ of patients treated for TB meningitis and contributed significantly to early deaths.

Conclusion. Inflammatory neurologic diseases are common in SSA but their prevalence and patterns differ from those reported in high-income countries. The explanation for this difference is not known but may be related to the high burden of infections, possibly providing insight into the role of inflammation and disease and fertile ground for further research.

\section{STUDY FUNDING}

No targeted funding reported.

\section{DISCLOSURE}

The author reports no disclosures relevant to the manuscript. Go to Neurology.org for full disclosures.

\section{REFERENCES}

1. Howlett W. Neurological infections. In: Neurology in Africa. Available at: http://www.uib.no/cih/en/resources/ neurology-in-africa. Accessed June 9, 2014.

2. Dean G. Annual incidence, prevalence and mortality of multiple sclerosis in white South-African-born and in white immigrants to South Africa. Br Med J 1967;2: 724-730.

3. Bhigjee AI, Moodley K, Ramkissoon K. Multiple sclerosis in KwaZulu Natal, South Africa: an epidemiological and clinical study. Mult Scler 2007;13:1095-1099.

4. Poser CM. Multiple sclerosis. In: Shakir RA, Newman PK, Poser CM, eds. Tropical Neurology. London: WB Saunders; 1996:437-455.

5. Osuntokun BO. The pattern of neurological illness in tropical Africa: experience at Ibadan, Nigeria. J Neurol Sci 1971;4:417-442.

6. Modi G, Mochan A, Modi M, Saffer D. Demyelinating disorder of the central nervous system occurring in black South Africans. J Neurol Neurosurg Psychiatry 2001;70: 500-505.

7. Zatjirua V, Butler J, Carr J, Henning F. Neuromyelitis optica and pulmonary tuberculosis: a case-control study. Int J Tuberculosis Lung Dis 2011;15:1675-1680. 
8. Heckmann JM, Owen EP, Little F. Myasthenia gravis in South Africans: racial differences in clinical manifestations. Neuromuscular Disord 2007;17:929-934.

9. Bateman K, Schinkel M, Little F, Liebenberg L, Vincent A, Heckmann JM. Incidence of seropositive myasthenia gravis in Cape Town and South Africa. South Afr Med J 2007;97:956-962.
10. Howlett WP, Vedeler CA, Nyland H, Aarli JA. GuillainBarre syndrome in northern Tanzania: a comparison of epidemiological and clinical findings with western Norway. Acta Neurol Scand 1996;93:44-49.

11. Thornton CT, Latif AS, Emmanuel JC. Guillain-Barre syndrome associated with human immunodeficiency virus infection in Zimbabwe. Neurology 1991;41:812-815. 


\title{
Neurology
}

\author{
Inflammatory neurologic disease in sub-Saharan Africa \\ William P. Howlett \\ Neurology 2014;83;656-658 \\ DOI 10.1212/WNL.0000000000000683
}

\section{This information is current as of August 11, 2014}

\section{Updated Information \& Services}

References

Citations

Subspecialty Collections

Permissions \& Licensing

Reprints including high resolution figures, can be found at: http://n.neurology.org/content/83/7/656.full

This article cites 9 articles, 3 of which you can access for free at: http://n.neurology.org/content/83/7/656.full\#ref-list-1

This article has been cited by 1 HighWire-hosted articles: http://n.neurology.org/content/83/7/656.full\#\#otherarticles

This article, along with others on similar topics, appears in the following collection(s):

\section{Post-infectious}

http://n.neurology.org/cgi/collection/postinfectious_

Information about reproducing this article in parts (figures,tables) or in its entirety can be found online at:

http://www.neurology.org/about/about_the_journal\#permissions

Information about ordering reprints can be found online:

http://n.neurology.org/subscribers/advertise

Neurology ${ }^{\circledR}$ is the official journal of the American Academy of Neurology. Published continuously since 1951, it is now a weekly with 48 issues per year. Copyright @ 2014 American Academy of Neurology. All rights reserved. Print ISSN: 0028-3878. Online ISSN: 1526-632X.

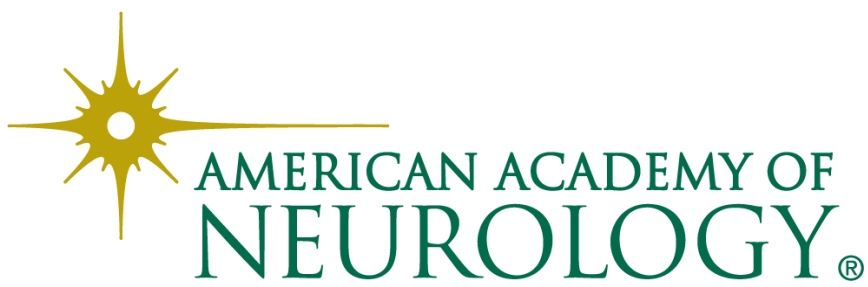

